\title{
A popularidade do skate durante os Jogos Olímpicos refletirá no seu uso como meio de transporte urbano no Brasil?
}

\author{
The popularity of skateboarding during the Olympic Games: will it reflect on its use as a means of \\ urban transport in Brazil?
}

La popularidad del skate durante los Juegos Olímpicos: ¿se reflejará en su uso como medio de transporte urbano en Brasil?

\begin{abstract}
Resumo
A inserção do skate como modalidade esportiva nos Jogos Olímpicos de Verão de 2020 lança luz sobre uma prática costumeiramente marginalizada no Brasil. A fim de avaliar o impacto do skate nos Jogos Olímpicos no interesse dos brasileiros, este estudo analisou os volumes de buscas no Google Trends e os comparou com dados globais. Após coleta e tratamento dos dados, identificou-se que o interesse médio pelo termo skate no Brasil antes dos Jogos Olímpicos era 4,5 vezes inferior à média mundial. Já durante o evento, o Brasil foi o país que mais se interessou pelo assunto - potencial consequência da conquista de medalhas por atletas brasileiros. Todavia, uma crescente popularidade do skate no Brasil evoca as dificuldades enfrentadas pelos praticantes da modalidade no país, como a falta de regulamentação. O Código de Trânsito Brasileiro não reconhece o skate como um veículo — expondo, assim, os usuários a riscos nas vias.
\end{abstract}

Palavras-chave: Skate; Transporte urbano; Transporte sustentável; Jogos Olímpicos.

\begin{abstract}
Introducing skateboarding as a sport in the 2020 summer Olympic Games sheds light on a practice usually marginalized, even in Brazil. To assess how Olympic Games' skateboarding impacted Brazilians' enthusiasm, this study analyzed search volumes on Google Trends and compared them with global data. After collecting and processing data, we identified that the average interest in skateboarding in Brazil before the Olympic Games was 4.5 times lower than the world average. During the event, Brazil was the country that most searched about skateboarding - a potential consequence of winning medals by Brazilian athletes. However, the growing popularity of skateboarding in Brazil evokes the difficulties that skateboarders face, such as the lack of regulation. The Brazilian Traffic Code does not recognize skateboarding as a vehicle, thus exposing users to risks on the roads.

Keywords: Skateboarding; Urban transport; Sustainable transport; Olympic Games.

\section{Resumen}

La inclusión del skateboarding como deporte en los Juegos Olímpicos de Verano de 2020 arroja luz sobre una práctica habitualmente marginada en Brasil. Para evaluar el impacto del skate en los Juegos Olímpicos en interés de los brasileños, este estudio analizó los volúmenes de búsqueda en Google Trends y los comparó con datos globales. Luego de recolectar y procesar datos, se identificó que el interés promedio por el término skate en Brasil antes de los Juegos Olímpicos era 4.5 veces menor que el promedio mundial. Durante el evento, Brasil fue el país más interesado en el tema, una posible consecuencia de la obtención de medallas por parte de los atletas brasileños. Sin embargo, la creciente popularidad del skate en Brasil evoca las dificultades que enfrentan los practicantes de este deporte en el país, como la falta de regulación. El Código de Tránsito Brasileño no reconoce el skate como vehículo, exponiendo así a los usuarios a riesgos en las carreteras.
\end{abstract}

Palabras clave: Skateboarding; Transporte urbano; Transporte sostenible; Juegos Olímpicos. 


\section{Introdução}

O skate surgiu na Califórnia nos anos 1950, chegando ao Brasil na década seguinte com o nome de "surfinho", dada a similaridade com o surfe (Honorato, 2004). Desenvolveu-se aliado à cultura punk, à transgressão e à rebeldia sendo, muitas vezes, associado à "anarquia urbana" (Carrança, 2021). Na década de 1980, Jânio Quadros, então prefeito de São Paulo (SP), chegou a proibir o skate no principal parque da cidade alegando que o esporte era uma ameaça a adultos, senhoras e crianças (Folha de S. Paulo, 1988). No entanto, a repressão sofrida pelo skate no século XX não impediu o crescimento da modalidade, que começou a sair dos parques e pistas para tomar as ruas.

O Relatório sobre a Lacuna de Emissões divulgado pela Organização das Nações Unidas (ONU, 2020) prevê um aumento de temperatura de $3^{\circ} \mathrm{C}$ até o fim do século, apesar da redução das emissões de Gases de Efeito Estufa (GEE) durante a pandemia de COVID-19. Esse aumento chega a superar, inclusive, as metas impostas pelo Acordo de Paris, em 2015. No Brasil, o transporte foi o principal emissor de CO2 no setor energético, responsável por emitir 200,2 milhões de toneladas de $\mathrm{CO}_{2}$ (49\% do total), de acordo com relatório divulgado pelo Sistema de Estimativas de Emissões de Gases de Efeito Estufa (SEEG, 2019). Dados esses números, o transporte urbano através do skate representa uma alternativa mais sustentável em relação aos veículos automotores.

Os Jogos Olímpicos de Verão de 2020 trouxeram, como grande novidade, a inclusão de três modalidades de esportes radicais: o surfe, a escalada e o skate. Proposta pelo país-sede, o Japão, e autorizada pelo Comitê Olímpico Internacional (COI), a adição teve como principal objetivo criar um apelo entre o público mais jovem. O skate, foco deste trabalho, foi disputado nas suas variações street - em que o skatista percorre uma pista que contém elementos que integram o ambiente urbano como escadas e corrimões - e park - em que as manobras são realizadas em uma pista oca com curvas sinuosas. A modalidade proporcionou ao Brasil três medalhas de prata: Kelvin Hoefler e Rayssa Leal, no street, e Pedro Barros, no park.

Muito além da premiação, o destaque do Brasil no skate nos Jogos Olímpicos representou um marco do início do interesse pelo esporte e, mais, trouxe à tona sua existência enquanto modo de transporte marginalizado pela lei no país.

Nesse contexto, este trabalho tem como objetivo analisar a possibilidade de popularização do skate entre os brasileiros devido à projeção de seu uso nos Jogos Olímpicos de Verão de 2020 e discutir o cenário do skate como meio de transporte urbano no Brasil.

\section{Metodologia}

A fim de analisar o impacto dos resultados obtidos pelos atletas brasileiros nos Jogos Olímpicos de Verão de 2020 na popularização do skate e o crescimento de seu uso como um meio de transporte, é analisado o interesse da pesquisa pelo termo "skate", no Brasil e no mundo, a partir do Google Trends - ferramenta do Google que indica a frequência com que um termo de pesquisa é buscado na web. Os números retornados pelo Google Trends não representam o volume absoluto de busca(s) por algum assunto, mas sim o volume relativo de busca(s) a partir de uma escala que oscila entre 0 (volume de buscas inferior a $1 \%$ do montante de buscas do pico de popularidade) e 100 (pico de popularidade de um termo).

A página web da ferramenta (acessível a partir do endereço https://trends.google.com.br/) sintetiza os dados de buscas por meio de gráficos (frequência de busca em função do tempo), mapas (região que mais buscou sobre o assunto analisado dentro de um período de tempo) e listas de assuntos e pesquisas relacionadas, havendo a possibilidade de baixar tais dados como arquivos .csv (valores listados com um separador específico). Para permitir análises e comparações mais detalhadas, o Google Trends permite filtrar a análise de interesse considerando delimitações geográficas (níveis global, nacional e estadual), período de tempo (horas, dias, meses, anos, períodos personalizados etc.), categorias temáticas (como artes e entretenimento, ciência, notícias etc.) e o local ou a forma de pesquisa (Google web, Google Shopping, pesquisa por imagem etc.). 
Como inicialmente apontado, definiu-se como termo de busca a palavra "skate" e avaliou-se o interesse pelo termo no Brasil e no mundo. Delimitou-se a busca para dois períodos distintos: um referente aos Jogos Olímpicos de Verão de 2020 (23/07/2021 a 08/08/2021), para avaliar a influência do evento no interesse por esse meio de transporte, e outro considerando um período de 5 anos anterior à data de encerramento desses Jogos (08/08/2016 a 08/08/2021), para averiguar o interesse médio no assunto e identificar outros picos que possam ter ocorrido. Como o skate não é considerado um veículo pelo CTB Código de Trânsito Brasileiro (Brasil, 1997), optou-se por avaliar o interesse pelo termo na opção "Todas as categorias" a partir de pesquisas na web.

\section{Resultados e Discussão}

Ao analisar os dados coletados a partir do Google Trends, pode-se perceber que o interesse pelo termo skate aumentou durante as competições dos Jogos Olímpicos de Verão de 2020 (Figura 1). Em nível mundial, o volume de buscas durante esses Jogos foi mais de três vezes superior ao volume de buscas usualmente realizadas.

Figura 1. Volume relativo de buscas pelo termo skate, em todo o mundo, nos últimos cinco anos (08/08/2016 a 08/08/2021).

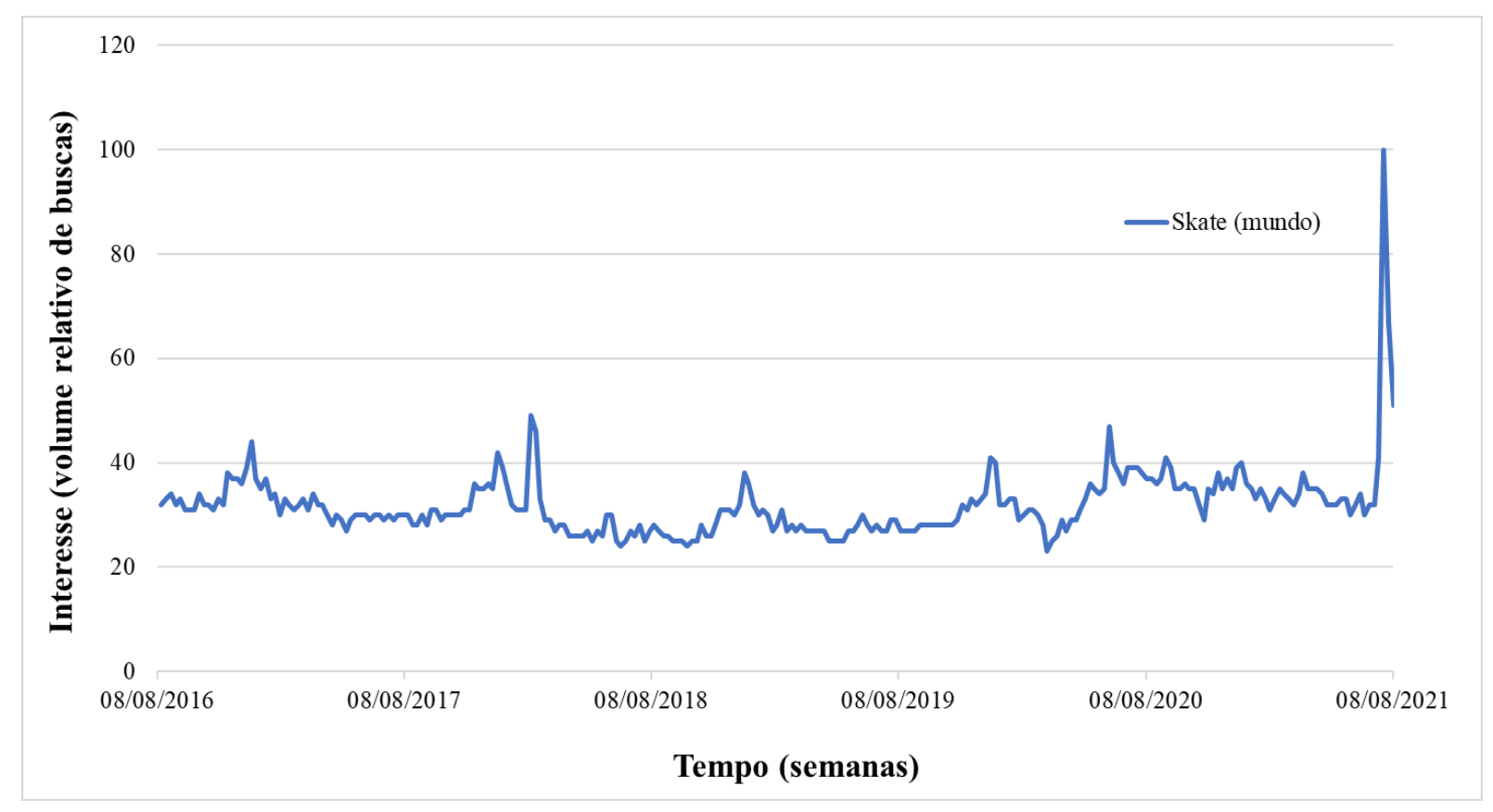

Fonte: Google (2021a).

Pode-se notar que antes dos Jogos Olímpicos de Verão de 2020, o volume de buscas pelo termo skate no Brasil era cerca de 14 vezes menor do que o volume de buscas na semana dos dias 25 e 26 de julho de 2021 - data das competições finais de skate street masculino e feminino, respectivamente (Figura 2). 
Figura 2. Volume relativo de buscas pelo termo skate no Brasil nos últimos cinco anos (08/08/2016 a 08/08/2021).

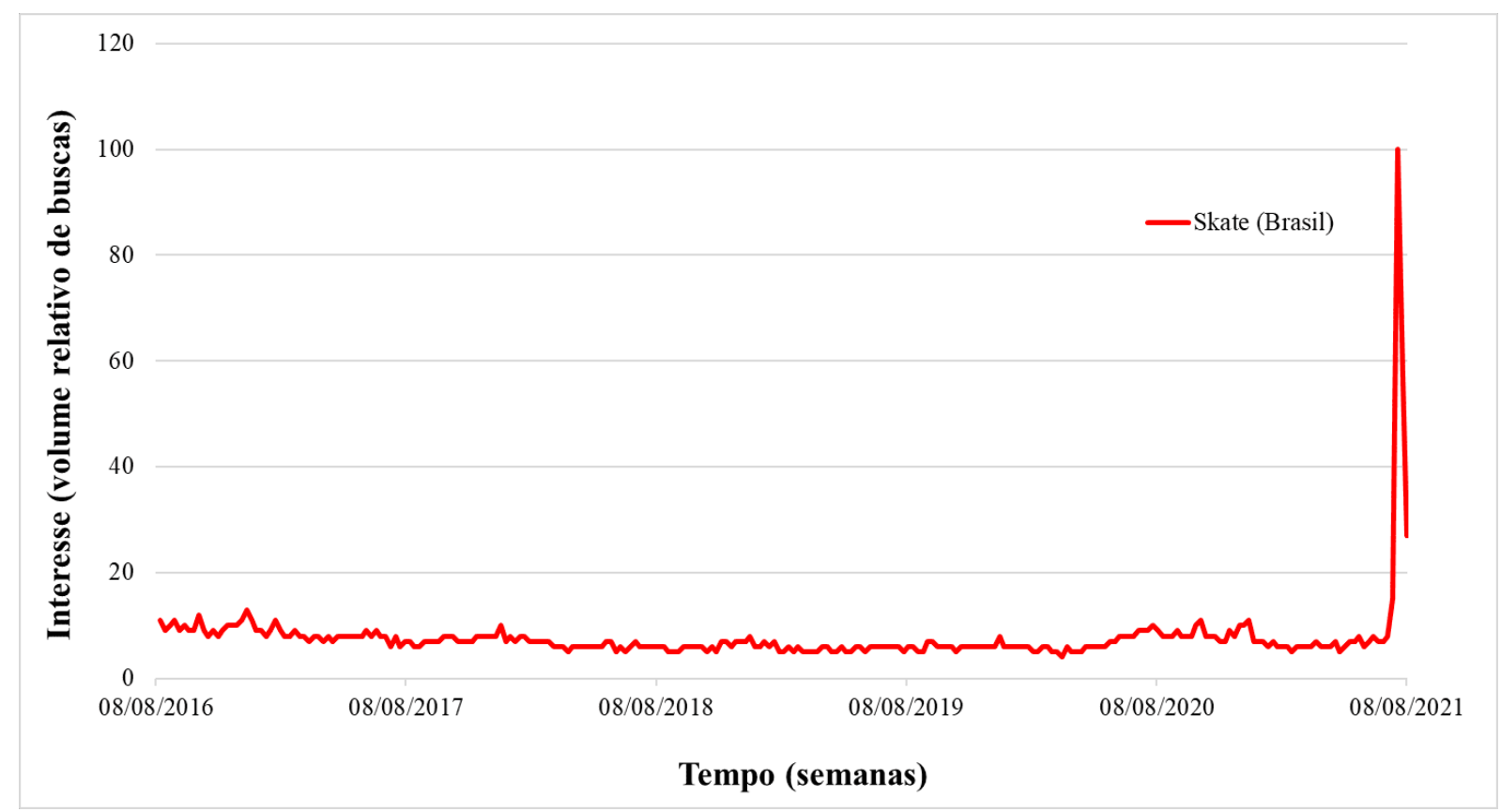

Fonte: Google (2021b).

Tomando-se o volume relativo de buscas para os contextos mundial e brasileiro, vê-se que o interesse geral relativo pelo skate no Brasil está abaixo da média mundial (desconsiderando o pico durante os Jogos Olímpicos de Verão de 2020) podendo-se observar, ainda, que o volume relativo de buscas pelo termo skate no Brasil é cerca de 4,5 vezes inferior ao volume relativo de buscas a nível mundial. Esse cenário pode estar associado ao período em que o skate começou a se difundir em terras brasileiras: com o advento do Governo Militar, a partir de 1964, e a consequente manutenção da visão conservadora do espaço urbano como um ambiente ordeiro, muitas cidades brasileiras reprimiram o uso do skate — tanto para fins recreativos quanto para fins de mobilidade urbana — devido à associação dessa prática com preceitos antiautoritários da cultura punk (Brandão, 2008; Carrança, 2021).

Considerando agora as buscas pelo termo skate durante o período dos Jogos Olímpicos de Verão de 2020, identificouse picos de interesse nos dias 26 de julho e 05 de agosto de 2021 — dias das competições finais, respectivamente, de skate street e de skate park.

A Figura 3 nos mostra o perfil de buscas pelo termo em se considerando o âmbito mundial, com sensível preferência pela modalidade street. 
Figura 3. Volume relativo de buscas pelo termo skate no mundo durante os Jogos Olímpicos de Verão de 2020 (23/07/2021 a 08/08/2021).

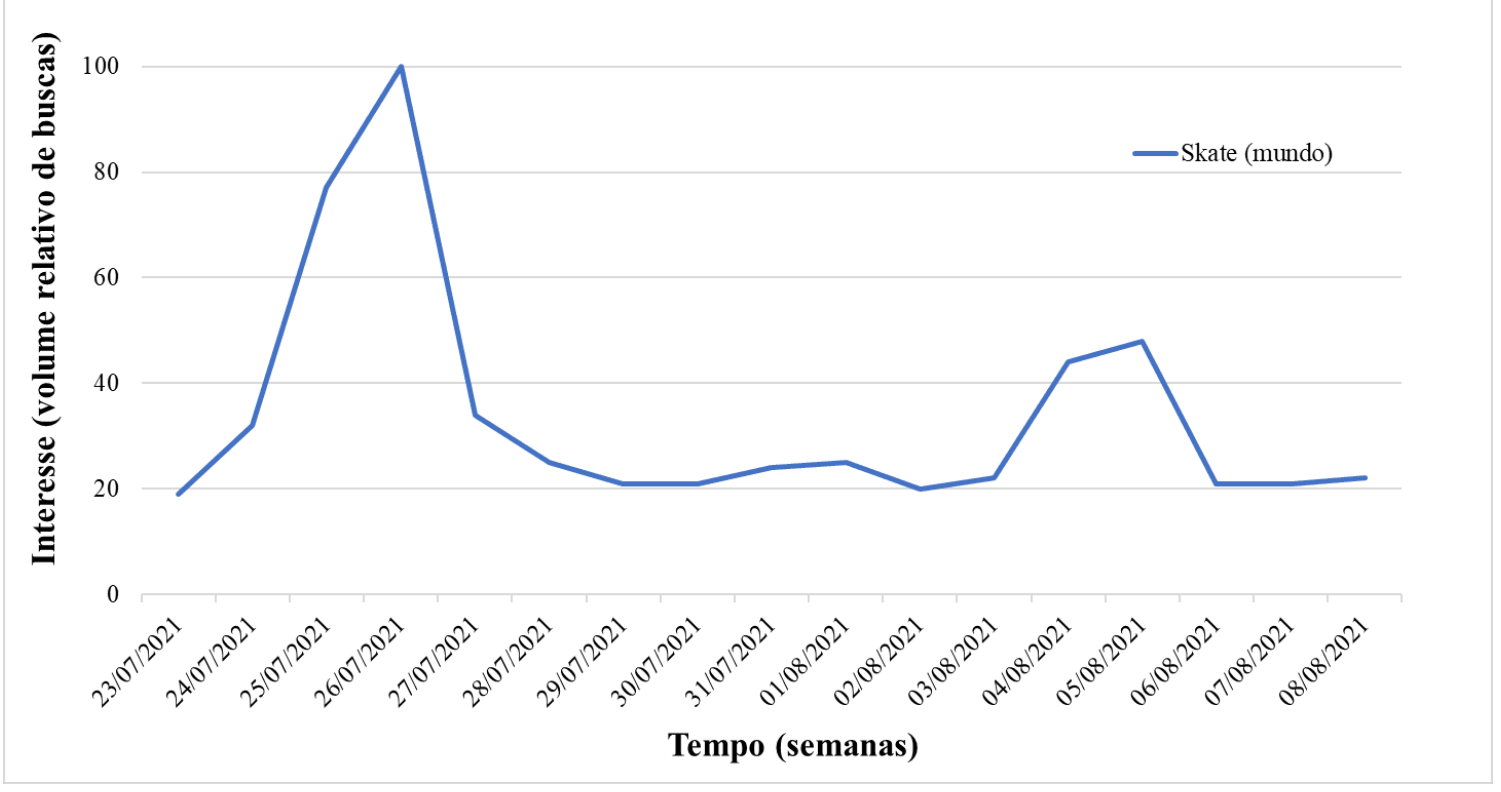

Fonte: Google (2021c).

$\mathrm{O}$ interesse pela modalidade street mostrou-se cerca de duas vezes superior ao interesse pela modalidade park. Isto pode estar atrelado ao fato de que as competições de street foram realizadas durante um fim de semana, enquanto que as de park ocorreram em dias úteis.

A Figura 4 apresenta o perfil de buscas pelo termo skate, agora no Brasil, durante as finais das modalidades, perfil este em total consonância com as tendências mundiais.

Figura 4. Volume relativo de buscas pelo termo skate no Brasil durante os Jogos Olímpicos de Verão de 2020 (23/07/2021 a 08/08/2021).

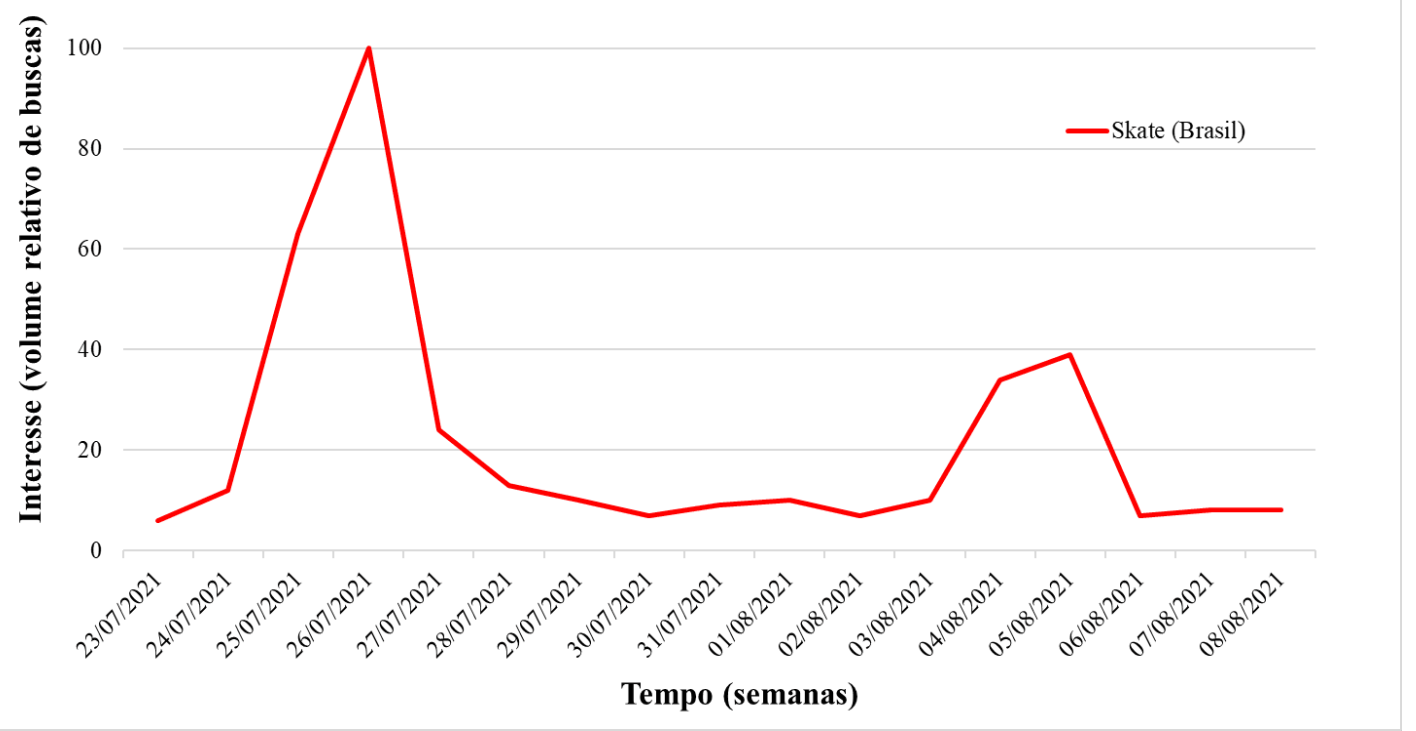

Fonte: Google (2021d). 
Esta distribuição, em ambos os perfis, com uma redução do interesse pela modalidade park, pode ser explicada não por motivos de qualidade dos atletas ou preferência por esta ou aquela modalidade, mas, sim, pela diferença de fuso horário que no Brasil, considerado o horário oficial de Brasília, é de 12 horas. Assim, os eventos ocorreram nas madrugadas, sendo que os da modalidade park ocorreram durante a madrugada em dias úteis.

A conquista de três medalhas de prata na nova modalidade olímpica pode ter contribuído para a predominância relativa de buscas no Brasil quando comparado a outros países (Figura 5). Considerando o volume relativo de buscas, o Brasil buscou o termo skate na web cerca de 2,6 vezes mais que o segundo país que mais se interessou pelo termo, Portugal (38\%).

Figura 5. Volume relativo de buscas pelo termo skate no mundo (A) e no Brasil, com destaque para as unidades federativas (B), durante os Jogos Olímpicos de Verão de 2020 (23/07/2021 a 08/08/2021).

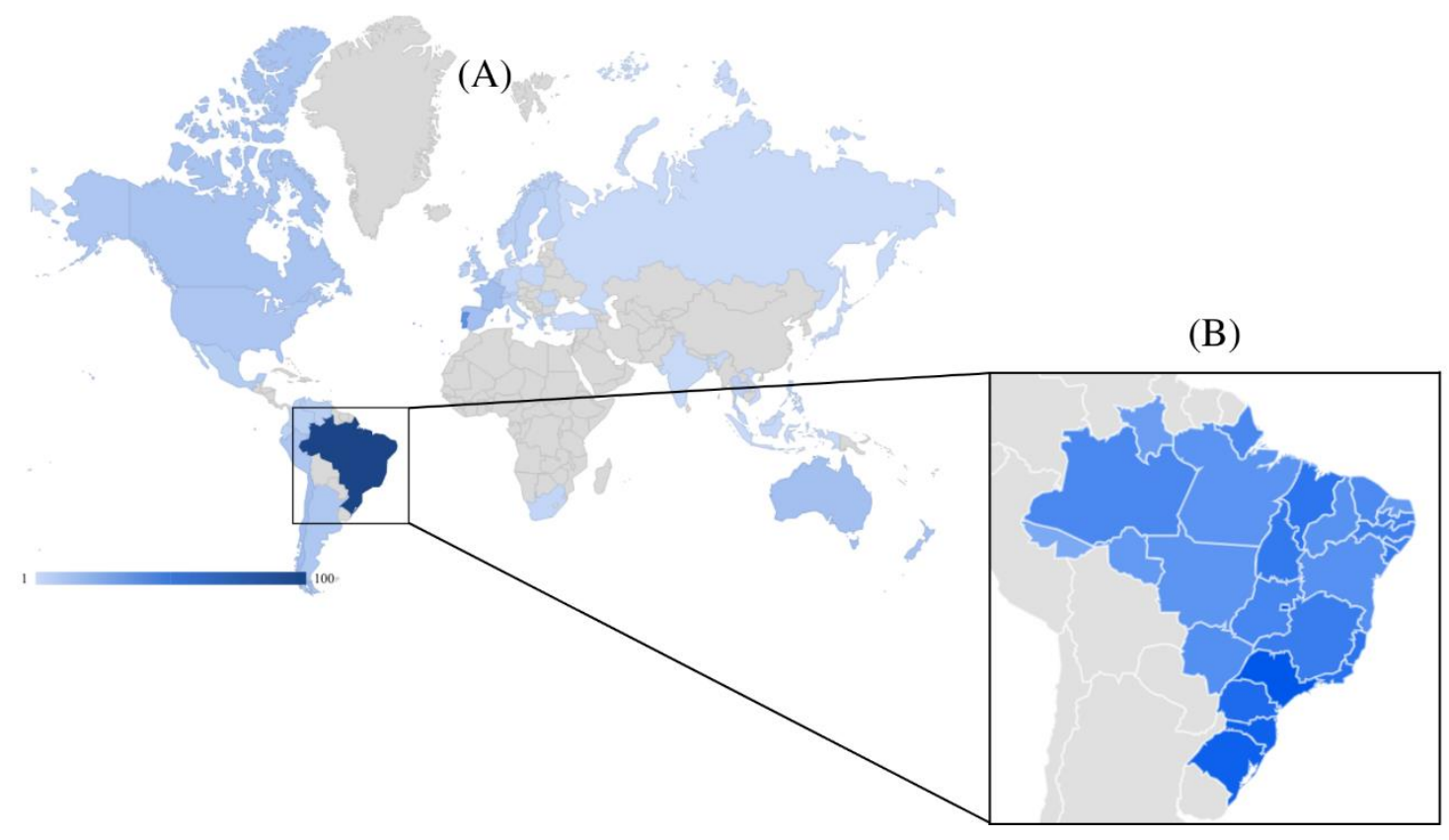

Fonte: Adaptado de Google (2021c; 2021d).

O aumento repentino da popularidade do skate pode contribuir para uma maior difusão desse esporte no Brasil. Dados de 2015, de pesquisa encomendada pela Confederação Brasileira de Skate (CBSk), apontam que, em 11\% dos domicílios brasileiros, há pelo menos um morador que pratica ou anda de skate, o que representa cerca de 8.449 .980 brasileiros (CBSk, 2015). A mesma pesquisa indicou um aumento expressivo em relação ao ano de 2009, quando os usuários da modalidade estavam presentes em apenas 5\% dos domić́lios brasileiros. O levantamento, no entanto, não difere se o praticante usa o skate para lazer ou para se locomover. Ainda assim, o vasto crescimento da modalidade não implicou na regulamentação deste meio de transporte quanto ao CTB. Entre os transportes não motorizados, o CTB destaca apenas as bicicletas, em seu artigo 59, e os veículos de tração animal, em seu artigo 52 (Brasil, 1997).

Não obstante, a regulamentação do skate como meio de transporte já é realidade em outros países, seja através de leis mais amplas ou mais específicas. Na Califórnia, onde a modalidade surgiu, é facultado que cada região restrinja ou especifique as condições de uso do skate, mas o uso de capacetes por praticantes menores de 18 anos deve ser respeitado em todo o estado (California, 2016; California, 2019). A medida é interessante dada a capacidade de um capacete reduzir em $85 \%$ o risco de ferimentos na cabeça e em $88 \%$ os danos gerados no cérebro após um acidente (Stanford Children's, 2021) 
Uma eventual regulamentação se torna ainda mais relevante ao analisar os perfis de idade dos praticantes de skate no Brasil. No país como um todo, a média de idade de quem usa a modalidade é de 15 anos e chega a ser de apenas 12 anos na região Nordeste (Figura 6). Além disso, crianças de até 10 anos representam 26\% dos praticantes de skate no Brasil, comparados a 17\% de adultos maiores de 21 anos (Figura 7).

Figura 6. Idade média dos praticantes de skate em cada região demográfica do Brasil.

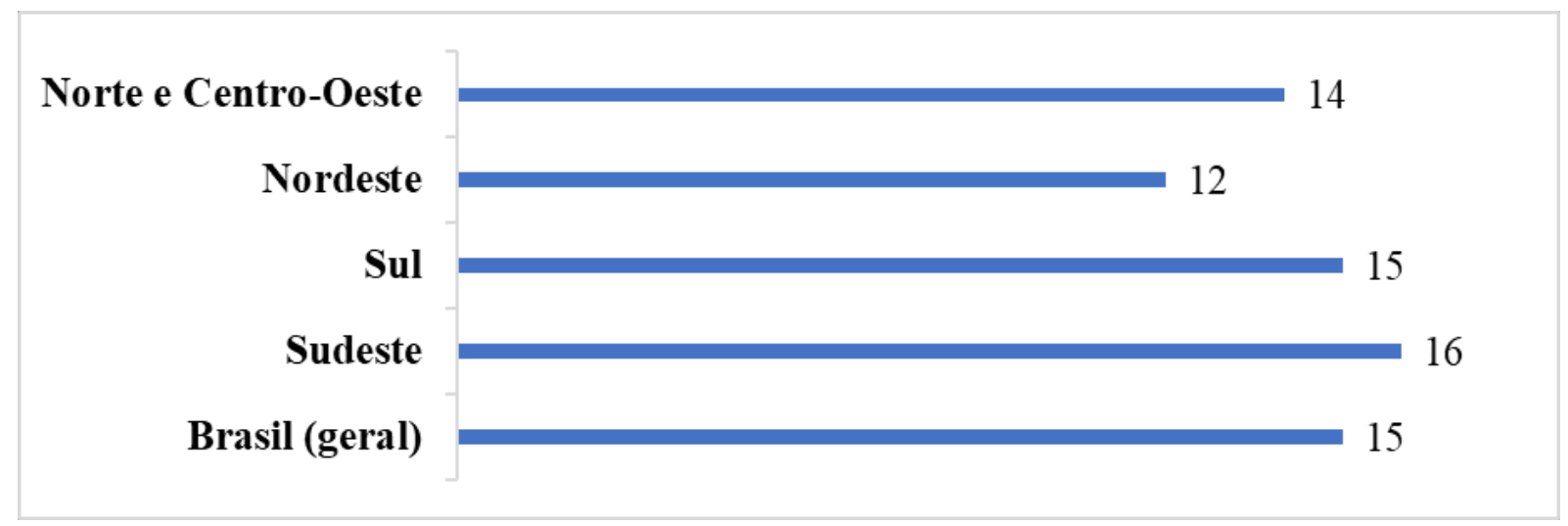

Fonte: CBSk (2015).

Figura 7. Porcentagens das idades dos praticantes de skate em cada região demográfica do Brasil.

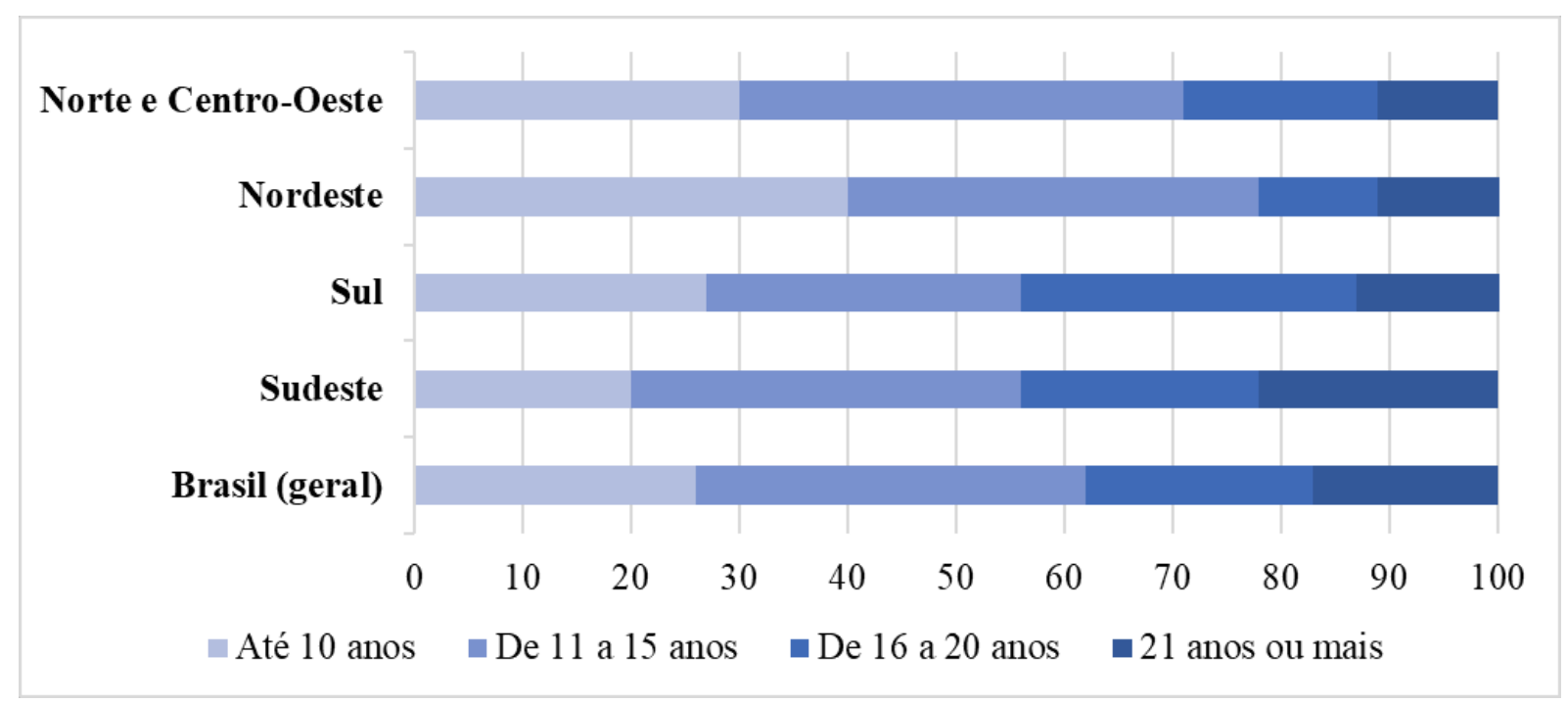

Fonte: CBSk (2015).

Dada a falta de regulamentação, não há exigências de que o público praticante de skate use equipamentos de proteção — como capacetes e joelheiras —, tampouco são previstos espaços nas vias para o trânsito de skate. Dessa forma, as precárias condições enfrentadas pelos usuários da modalidade expõem o público em questão a riscos de acidente e são contrárias ao que prevê o Estatuto da Criança e do Adolescente (ECA), ao garantir o direito à vida e à saúde para os mais jovens (Brasil, 1990).

O fator segurança, no entanto, ainda precisa ser analisado a partir de outro viés. Ao comparar o skate com outros veículos regulamentados pelo CTB, observa-se que ele não possui freio e possui dificuldade para fazer curvas. Fatores como esses fazem com que as companhias responsáveis por gerenciar os sistemas de tráfego da cidade, como a Companhia de Engenharia de Tráfego (CET), em São Paulo, desestimulem o uso do skate como meio de transporte, visto que ele gera riscos à segurança do próprio skatista e também de motoristas, motociclistas e pedestres (Torres, 2021). Por isso, antes de se discutir a 
validação desse meio de transporte nas vias compartilhadas, devem-se estabelecer as condições de segurança para que os benefícios do uso do skate para se transportar superem os riscos (Extra, 2021).

Assim, a premência da prática do skate, tanto para lazer como para transporte, por um público mais jovem deveria ser levada em conta nas câmaras legislativas brasileiras a fim de se pensar políticas públicas que garantam infraestrutura e segurança para o uso do skate em meio urbano - inclusive como um meio de locomoção sustentável.

\section{Considerações Finais}

Após analisar dados de busca coletados no Google Trends, percebe-se que o interesse pelo termo skate no Brasil disparou durante o período dos Jogos Olímpicos de Verão de 2020. Em um contexto anterior a esse período, foi constatada uma baixa popularidade da modalidade. Com isso, espera-se que o número de praticantes de skate aumente em virtude da notoriedade do esporte.

Estudos futuros poderão identificar se a popularidade das pesquisas pela modalidade irá, de fato, influenciar para que haja um aumento de usuários de skate. Ademais, pesquisas que determinem separadamente o número de praticantes que utilizam o skate para transporte e para lazer poderiam ser úteis para que análises como a realizada nesse artigo sejam mais eficazes.

Ademais, o momento enaltece as más condições enfrentadas pelos praticantes de skate no país; o público praticante lida com a falta de regulamentação do skate como um meio de transporte. Com esse descaso, não há leis que delimitam a parte das vias a serem utilizadas pelo skate, tampouco que regem os equipamentos de segurança que devem ser usados pelos praticantes da modalidade. Visto que cerca de $52 \%$ dos brasileiros que fazem uso do skate possuem idade inferior a 16 anos, torna-se premente a sua regulação enquanto meio de transporte não-convencional.

\section{Referências}

Brasil (1990). Lei $n^{\circ}$ 8.069, de 13 de julho de 1990. http://www.planalto.gov.br/ccivil_03/leis/18069.htm

Brasil (1997). Lei $n^{\circ}$ 9.503, de 23 de setembro de 1997. http://www.planalto.gov.br/ccivil_03/leis/19503compilado.htm

Brandão, L. (2008). Entre a marginalização e a esportivização: elementos para uma história da juventude skatista do Brasil. Recorde: Revista de História de Esporte, 1 (2), 1-24.

California (2016). Vehicle Code - VEH Division 11 Rules of The Road [21000 - 23336] Chapter 1. Obedience to and Effect of Traffic Laws [21000 - 21296] Article 3. Local Regulation [21100 - 21118]. https://leginfo.legislature.ca.gov/faces/codes_displaySection.xhtml?sectionNum=21113.\&lawCode=VEH

California (2019). Vehicle Code - VEH Division 11 Rules of The Road [21000 - 23336] Chapter 1. Obedience to and Effect of Traffic Laws [21000 - 21296] Article 4. Operation of Bicycles [21200 - 21213]. https://leginfo.legislature.ca.gov/faces/codes_displaySection.xhtml?sectionNum=21212.\&lawCode=VEH

Carrança, Thais (2021). Olimpíada de Tóquio 2021: como o skate foi da proibição às medalhas no Brasil. BBC. https://www.bbc.com/portuguese/geral57979486

CBSk (2015). Pesquisa Datafolha 2015. http://www.cbsk.com.br/uploads/repositorio/pesquisadatafolha2015.pdf

Extra (2021) Não regulamentado, skate é usado como meio de transporte. https://www.extraguarapuava.com.br/ultimas-noticias/nao-regulamentado-skate-eusado-como-meio-de-transporte/

Folha de S. Paulo (1988). Jânio proíbe skate e e no e https://acervo.folha.com.br/leitor.do?numero=10239\&anchor=4147763\&origem=busca\&originURL=\&pd=97e35b17039fb91979d4f9c9f45a2b5f

Google (2021a). Google Trends. https://trends.google.com.br/trends/explore?date=2016-08-08\%202021-08-08\&q=skate

Google (2021b). Google Trends. https://trends.google.com.br/trends/explore?date=2016-08-08\%202021-08-08\&geo=BR\&q=skate

Google (2021c). Google Trends. https://trends.google.com.br/trends/explore?date=2021-07-23\%202021-08-08\&q=skate

Google (2021d). Google Trends. https://trends.google.com.br/trends/explore?date=2021-07-23\%202021-08-08\&geo=BR\&q=skate

Honorato, T. (2004). Uma História do Skate no Brasil: do Lazer à Esportivização. Anais do VII Encontro Regional de História, 1-14.

ONU (2020). Relatório sobre a Lacuna de Emissões. https://www.unep.org/pt-br/emissions-gap-report-2020 
Research, Society and Development, v. 11, n. 3, e14411326203, 2022

(CC BY 4.0) | ISSN 2525-3409 | DOI: http://dx.doi.org/10.33448/rsd-v11i3.26203

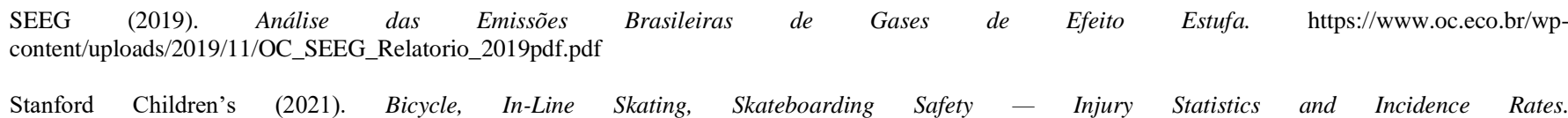
https://www.stanfordchildrens.org/en/topic/default?id=bicycle-in-line-skating-skateboarding-safety--injury-statistics-and-incidence-rates-90-P03008

Torres, B. (2021). Skate candidata-se a alternativa de transporte. https://namu.com.br/portal/sustentabilidade/cidades/skate-candidata-se-a-alternativa-detransporte/ 